\title{
Uncertainty in using chest computed tomography in early coronavirus disease (COVID-19)
}

\author{
Rujittika Mungmunpuntipantip, PhD • Viroj Wiwanitkit, MD
}

Received: 14 March 2020/Revised: 15 March 2020/ Accepted: 15 March 2020/Published online: 2 April 2020

(C) Canadian Anesthesiologists' Society 2020

\section{To the Editor,}

The title of a recent Images article in the Journal by Chen et $a l .^{1}$ describes chest computed tomography (CT) findings in a pregnant woman with coronavirus disease (COVID-19) as "early coronavirus disease." We argue that these findings are inconsistent with "early" COVID-19. Cases of COVID-19 were identified in Thailand shortly after its first appearance in China ${ }^{2}$; as of 14 March 2020, there have been 82 confirmed diagnoses of COVID-19 reported in Thailand. All Thai cases are confirmed by reverse transcriptase polymerase chain reaction (RT-PCR) in two reference labs, and all patients receive chest CT scans. Thirty-eight of the 82 cases were diagnosed during active screening for severe acute respiratory syndrome coronavirus 2 (SARS-CoV-2) in persons who had been in close contact to patients known to have COVID-19. Most of those screened were asymptomatic or reported only mild symptoms; none showed abnormal findings on chest CT scans. One asymptomatic Thai patient underwent general anesthesia for orthopedic surgery before being diagnosed with COVID-19 in the postoperative period. This case also had normal CT findings at the time of diagnosis.

$\mathrm{Hu}$ et al. reported that $29.2 \%$ of asymptomatic patients from China who were infected with SARS-CoV-2 and who

This letter is accompanied by a reply. Please see Can J Anesth 2020; 67: this issue.

R. Mungmunpuntipantip, $\mathrm{PhD}(\bowtie)$.

Medical Center, Bangkok, Thailand

e-mail: rujittika@gmail.com

V. Wiwanitkit, MD

Dr DY Patil University, Pune, India

Hainan Medical University, Haikou, China presented with no or mild symptoms at the time of diagnosis by RT-PCR test had a normal chest CT scan. ${ }^{3}$ Asymptomatic SARS-CoV-2 infection is possible and has been previously reported in Thailand and Croatia. ${ }^{4}$ COVID-19 may be asymptomatic in its early stages even though viral RNA can be detected by RT-PCR screening. ${ }^{4}$ We therefore discourage the consideration of CT findings when ruling out cases of COVID-19.

Conflicts of interest None.

Funding statement None.

Editorial responsibility This submission was handled by Dr. Hilary P. Grocott, Editor-in-Chief, Canadian Journal of Anesthesia.

\section{References}

1. Chen $R$, Chen J, Meng $Q$. Chest computed tomography images of early coronavirus disease (COVID-19). Can J Anesth 2020. DOI: https://doi.org/10.1007/s12630-020-01625-4.

2. Yasri S, Wiwanitkit V. Wuhan coronavirus outbreak and imported case. Adv Trop Med Pub Health Int 2020; 10: 1-2.

3. $H u$ Z, Song $C, X u C$, et al. Clinical characteristics of 24 asymptomatic infections with COVID-19 screened among close contacts in Nanjing, China. Sci China Life Sci 2020. DOI: https:// doi.org/10.1007/s11427-020-1661-4.

4. Joob S, Ronald M. Asymptomatic COVID-19: an important clinical consideration. Adv Lab Med Int 2020; 10: 4-5.

Publisher's Note Springer Nature remains neutral with regard to jurisdictional claims in published maps and institutional affiliations. 